\title{
NUMERICAL-FIELD ANALYSIS OF THE CHARACTERISTICS OF A THREE-PHASE MAGNETIC FIELD INDUCTOR FOR THE TREATMENT OF VARIOUS SUBSTANCES WITH CURRENT STABILIZATION
}

Introduction. A three-phase magnetic field inductor (MFI) similar to the asynchronous motor stator, which provides processing of various substances, is considered. This is done by means of oblong ferromagnetic elements moving with a rotating magnetic field and located in its cylindrical working chamber. Problem. The aim of the work is to develop the theory and conduct practical calculations of the parameters and characteristics of the MFI that connect the electromagnetic quantities and their phase relationships in the mode of its load. Methodology. The studies are carried out on the basis of numerical calculations of the magnetic field in the MFI taking into account the ferromagnetic elements in its working chamber. The calculation model of the chamber is represented by a homogeneous anisotropic magnetic medium for which the method of determining different magnetic permeabilities by its longitudinal and transverse axes is given. In order to obtain the characteristics of the presented MFI, the method of determining the electromagnetic parameters and phase relationships of the quantities accompanying its operation has been developed. Results. The theory and results of numerical-field analysis of electromagnetic quantities, their phase relationships and corresponding characteristics of three-phase MFI are presented. Calculations of characteristics are made for the inductor load mode depending on the phase shift of the magnetomotive force of the stator winding relative to the longitudinal axis of the chamber and while ensuring the constant value of the current of this winding. The characteristics include magnetic flux coupling, EMF and stator winding voltage, phase shifts between them and current, electromagnetic moment, input and output power, electrical and magnetic loss power, power factor and efficiency. Practical value. The technique of numerical-field calculations of electromagnetic quantities and their phase relationships is developed, and also the set of characteristics which should promote designing and perfection of inductors of the considered type is received. The presented technique is universal as it allows to display their cores practically of any shape. References 11, figures 10.

Key words: magnetic field inductor, asynchronous motor stator, theory, numerical-field calculations, electromagnetic quantities, phase relationships, characteristics.

Розглянуті теорія і результати чисельно-польового аналізу електромагнітних величин, їх фазових співвідношень $i$ відповідних характеристик трифазного індуктора магнітного поля. Індуктор подібний до статора асинхронного двигуна $і$ забезпечує обробку різних речовин. Це відбувається за допомогою довгастих феромагнітних елементів, цо знаходяться в його робочій камері і рухаються 3 обертовим магнітним полем. Розрахункова модель камери представлена анізотропним магнітним середовищем з різною магнітною проникністю по їі подовжсній $і$ поперечній осям. Розрахунки характеристик виконані в режсмі навантаження індуктора залежно від фазового зсуву магніторушійної сили обмотки статора відносно подовжньої осі камери і при забезпеченні незмінної величини струму цієї обмотки. Отримана сукупність характеристик повинна сприяти проектуванню і вдосконаленню індукторів розглянутого типу. Надана методика є універсальною і дозволяє відображувати їх осердя практично будь-якої форми. Бібл. 11, рис. 10 .

Ключові слова: індуктор магнітного поля, статор асинхронного двигуна, теорія, чисельно-польові розрахунки, електромагнітні величини, фазові співвідношення, характеристики.

Рассмотрены теория и результаты численно-полевого анализа электромагнитных величин, их фазовых соотношений и соответствующих характеристик трехфазного индуктора магнитного поля. Индуктор подобен статору асинхронного двигателя и обеспечивает обработку различных веществ. Это происходит с помощью движущихся с вращающимся магнитным полем продолговатых ферромагнитных элементов, находящихся в его рабочей камере. Расчетная модель камеры представлена анизотропной магнитной средой с разными магнитными проницаемостями по ее продольной и поперечной осям. Расчеты характеристик проведены в режиме нагрузки индуктора в зависимости от фазового сдвига магнитодвижущей силь обмотки статора относительно продольной оси камеры и при обеспечении неизменной величины тока этой обмотки. Полученная совокупность характеристик должна способствовать проектированию и совершенствованию индукторов рассмотренного типа. Представленная методика является универсальной, так как позволяет отображать их сердечники практически любой формы. Библ. 11, рис. 10.

Ключевые слова: индуктор магнитного поля, статор асинхронного двигателя, теория, численно-полевые расчеты, электромагнитные величины, фазовые соотношения, характеристики.

Introduction. In a number of industries, magnetic mixers and separators are used to provide technological processes for mixing different mixtures or separating small objects with different electromagnetic properties [1-3]. The structure and nature of magnetic fields (MFs), which provide these processes, are very diverse. Among them are rotating MFs, which are excited by an inductor similar to the stator of a three-phase asynchronous motor (TAM).
The difference between such a magnetic field inductor (MFI) and a TAM is that instead of a rotor, a working chamber (WC) is located inside the stator, through which a liquid or loose dry mixture is passed that needs to be processed. This is carried out using small ferromagnetic elements (FEs) moving with a rotating MF and creating the so-called «vortex layer» in the $\mathrm{WC}[1,3]$. It is assumed that the FEs are made, for example, in the 
form of needles or short pieces of iron wire, and they are uniformly distributed over the WC, the thin-walled shell of which is made of non-magnetic material and does not interact with MF.

An analysis of the literature shows that MFIs, despite the wide range of applications in various industries, is still not well understood. The fact is that the study of their electromagnetic parameters is carried out, as a rule, based on the theory of magnetic circuits. But in conditions of very large gaps and anisotropic lowmagnetic space, the representation of the MFI structure by several homogeneous sections of the magnetic circuit is problematic.

New opportunities in research and improvement of the design of MFI appeared with the development of software for numerical calculations of MF. Their effectiveness for MFI was already shown in [4] when analyzing the $\mathrm{MF}$ in its transverse and longitudinal sections based on plane-orthogonal calculation models.

A working tool for the numerical calculation of the MF in [4] and in this work, a publicly available and widespread FEMM code [5] was adopted.

In the aforementioned works, MF calculations are limited to considering the ideal idling (II) mode, i.e. without the presence in the working chamber of MFI FE. These studies have provided useful information, but cannot be the end result. More advanced calculations should be aimed at studying the electromagnetic parameters and characteristics of the MFI in the load mode, which will show the essence of the operation of the MFI as part of the main device - the mixer or separator. And here the main problem is accounting of the filling of the working chamber with the FE, providing the working process.

Therefore, the goal of this work is to study the characteristics of the MFI in its load mode based on numerical calculations of the MF taking into account the weakly magnetic medium in its working chamber. For this, the relations of electromagnetic parameters and phase quantities in the presented MFI with a rotating magnetic field created by a three-phase winding in a working chamber filled with FE are derived.

Object of study. The electromagnetic system of the MFI is the same as in [4]. It is shown in Fig. 1 only by its cross section, which is enough to achieve the goal of this work. Rectangular $(x, y)$ and the polar $(r, \alpha)$ coordinate systems with the origin of the angle from the $y$ axis are here designated and further used.

For technological reasons, the MFI parameters were set: the radius of the working chamber $r_{r e}=0.15 \mathrm{~m}$, the active length along the axial axis $l_{a}=0.3 \mathrm{~m}$. The MF inside the $\mathrm{WC}$ is distributed almost uniformly with magnetic flux density (MFD) in the center of $0.24 \mathrm{~T}$ in the ideal idle move. For this mode, the stator voltage and current are considered nominal.

The remaining parameters of the inductor are calculated by a technique close to the classical one for TAM [6], taking into account the absence of a rotor. Of the main parameters of the inductor, we present: the nominal phase voltage $U_{s N}=220 \mathrm{~V}$ and current $I_{s N}=950$ A, the frequency $f_{s}=50 \mathrm{~Hz}$. It has the number of phases $m_{s}=3$ and pairs of poles $p=1$, the number of slots
$Q_{s}=42$; the number of consecutive turns of the phase winding $N_{s}=28$. The radius of the bore of the core of the inductor $r_{s i}$ is $0.175 \mathrm{~m}$, since it should be slightly larger than the radius of the $\mathrm{WC}$ in order to exclude from it an annular gap with insufficiently homogeneous MF. The inductor winding is two-layer, distributed, with relative shortening $\beta_{s}=18 / 21$, the connection circuit is «star».

The MFI core is made of 2013 electrical steel, the sheet thickness is $0.5 \mathrm{~mm}$, the filling factor $K_{F e}=0.97$.

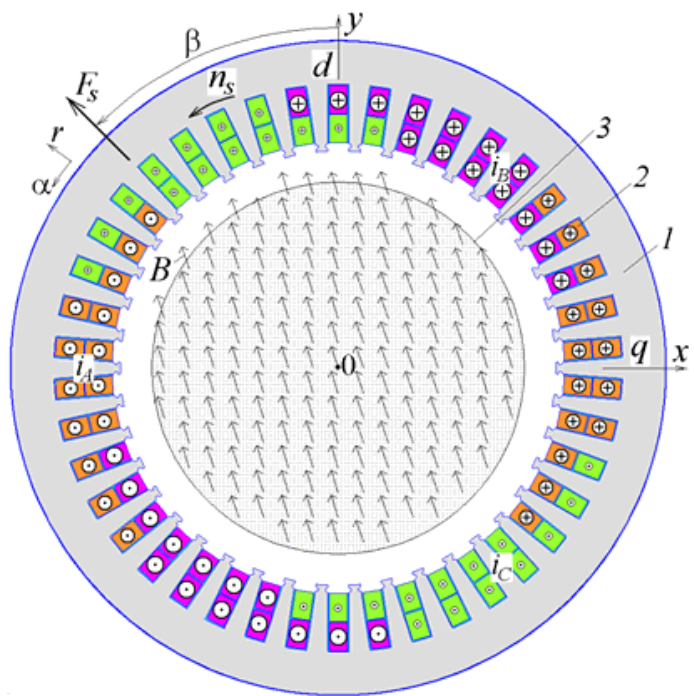

Fig. 1. Electromagnetic system of the MFI: 1 - laminated core; 2 - three-phase winding; 3 - working chamber

Fundamentals of numerical-field calculations. The source of a rotating MF in a MFI is a three-phase symmetric system of currents in the stator phase winding rods (Fig. 1):

$$
\begin{gathered}
i_{A}=I_{m} \cos (\omega t+\beta) ; \\
i_{B}=I_{m} \cos (\omega t-2 / 3 \pi+\beta) ; \\
i_{C}=I_{m} \cos (\omega t+2 / 3 \pi+\beta),
\end{gathered}
$$

where $I_{m}=\sqrt{2} I_{s}$ is the amplitude of the currents in the stator winding rods at the current value of the phase currents $I_{s} ; \omega=2 \pi f_{s}$ is the angular frequency; $t$ is the time; $\beta$ is the initial phase of the currents, which sets the necessary for the specific mode of calculating of the MF shift of the direction of the MMF of the stator winding $F_{s}$ from the $y$ axis.

Figure 1 shows the directions of currents in the winding rods at $t=0$ and $\beta=45^{\circ}$, and also shows the scaled distribution of the MFD vectors $B$ in the corresponding load mode, in which the MF rotates with frequency $n_{s}$. It can be seen that the MF in the $\mathrm{WC}$ is almost uniform. As for the MMF of the stator winding $F_{s}$, it is oriented clearly at a given angle $\beta$.

The MF of the inductor in its central cross section is described by the well-known 2D differential equation:

$$
\operatorname{rot}\left[\frac{1}{\mu_{e}} \operatorname{rot}\left(\vec{k} A_{z}\right)\right]=\vec{k} J_{z},
$$

where $A_{z}, J_{z}$ are the axial components of the magnetic vector potential (MVP) and current density, respectively; $\vec{k}$ is the unit vector along the axial axis $z ; \mu_{e}$ is the absolute magnetic permeability (AMP). 
The research tool presented to be the numerical calculations of MFs by the Finite Element Method using the FEMM code [5] with the control it by the created Lua script like [7].

When calculating the MF, the distribution of AMP in the laminated steel core and non-magnetic space is taken into account by the well-known method. In the MFI, the problem of taking into account the magnetic properties of the medium located in the WC is new. To achieve the goal of this work, a solution to the problem arisen is necessary. A separate stage of this work is devoted to this, which we preface with the description of the state of the environment of the WC.

The principle of operation of the MFI and the magnetic state of its WC. Oblong FEs in the WC tend to be located along the lines of force of the MF and, therefore, in the direction of the vectors of the MFD. However, under the influence of the braking effect of the medium being processed, between the directions of the magnetic field and the elements rotating together, a certain angular displacement should be formed. This is a condition for the occurrence of the electromagnetic torque (EMT) $M_{e m}$, which affects the FEs, on which the intensity and quality of technological processing of heterogeneous mixtures depend.

In fact, the EMT in the MFI is reactive, and the principle of operation of the MFI corresponds to the principle of operation of a synchronous motor [8]. By analogy with synchronous machines, in the WC, the longitudinal axis $d$ is assigned in the direction of FEs orientation, and the transverse axis $q$ is perpendicular to it. In the steady-state operating mode, the axes rotate together with these elements and the MF.

In Fig. 1, where a «snapshot» of electromagnetic quantities is shown a priori, the longitudinal axis $d$ coincides with the $y$ axis. The magnetic flux density vectors $B$ are shifted in an angle from the $d$ axis to the direction of rotation of the MF, and the MMF vector $F_{s}$ «goes» in front, as the «leading» everything else.

An array of coordinately oriented FEs leads to a difference in the magnetic properties inside the WC in different directions, which is expressed by magnetic anisotropy. Along the longitudinal $d$ and transverse $q$ axes indicated in Fig. 1, different values of the AMP components $\mu_{d}$ and $\mu_{q}$ turn out to be. They depend on the configuration, relative position, and concentration of FEs.

Determination of the equivalent magnetic properties of the MFI working chamber. Under the described conditions, this task is very complex and not strictly determined in view of the possible «element» of the FEs distribution in the WC. Therefore, in principle, at this stage, its approximate solution seems achievable. An idealized model of filling the WC is proposed here, and an appropriate method for determining its equivalent magnetic properties, which can be used in the calculation model of the MFI as a whole, is developed.

The initial assumptions for the formation of the magnetic properties of the WC are:

- all FEs in the MFI are parallel to each other, which is natural under the influence of a homogeneous magnetic $\mathrm{MF}$;
- FEs are distributed uniformly over the volume of the WC with a given displacement relative to each other;

- the magnetic properties of the medium in the cross section of the WC are anisotropic along mutually perpendicular axes: longitudinal $d$ and transverse $q$;

- the discrete magnetic medium of the WC is replaced by a continuous medium with equivalent magnetic permeabilities $\mu_{d}$ and $\mu_{q}$ along the indicated axes;

- the MF in the WC is rather weak and the properties of the FEs correspond to the initial sections of their magnetization curves, therefore, the values of $\mu_{d}$ and $\mu_{q}$ in the calculation of the MF in MFI practically do not change.

In the described situation, the problem of determining the AMP components $\mu_{d}$ and $\mu_{q}$ for a given size and relative position of the FEs is solved on the basis of numerical calculations of the MF in the idealized model of filling the WC shown in Fig. 2.
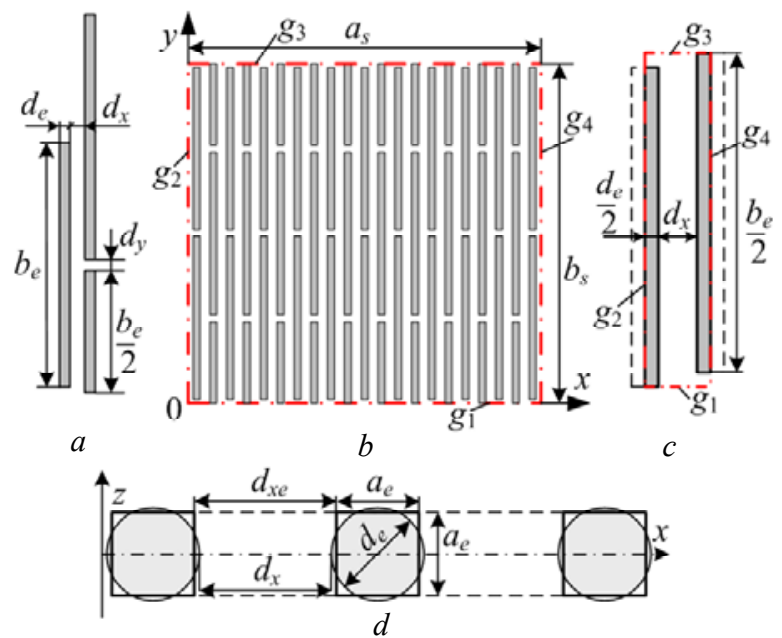

Fig. 2. Calculation model of the working chamber

In Fig. 2, $a$ the basic triple of the FEs is shown with the designation of the required minimum size, which can vary. From these elements, the filling of the entire calculation model is constructed, as, for example, in Fig. 2,b. In the common space of the WC, from which the calculation model is extracted, the boundary lines $g_{1}, g_{2}$, $g_{3}$ and $g_{4}$ should be considered as lines of symmetry or periodicity. In principle, the calculation model shown in Fig. 2,c, can be minimal, but it is not as clear as in Fig. $2, b$.

The key to forming the filling of the working chamber are the diameter $d_{e}$ and the height $b_{e}$ of the FE, as well as the gaps $d_{x}$ и $d_{y}$ between them. At the upper and lower borders there are halves of complete elements.

To fully reproduce the calculation model (Fig. 2,b), it is enough to set also the number of elements $n_{y}$ by its height. In Fig. 2,b, for clarity, the option is given for $n_{y}=2$, but the correct results will be obtained also for a different value of $n_{y}$ - the main thing is that the stated symmetry conditions are observed. The remaining parameters of the $\mathrm{WC}$, including the number of elements $m_{x}$ along the width of the WC, were found with the condition that $a_{s} \approx b_{s}$.

To ensure the operation of the FEMM code, a Lua script has been compiled that automatically calculates the 
parameters of the WC, builds its geometric model and organizes further calculations, as presented, for example, in [7] and a number of other works of the authors of this paper.

In cross section of the calculation model (Fig. 2,b) the MF is described by equation (2) and is calculated as plane-parallel. This means that, along the axial coordinate, the structure of the model should not change, which is not the case with round FE sections in the $x z$ plane (Fig. 2d). To get around this, round sections are replaced by square ones with side $a_{e}$ determined from the condition of preserving the cross-sectional area, namely: $a_{e}=0,5 \sqrt{\pi} d_{e}$. Accordingly, the equivalent gap between the elements along the width of the chamber $d_{x e}=d_{x}+d_{e}-a_{e}$ is recalculated.

For the calculation model, the total cross-sectional area $S_{s}=a_{s} b_{s}$ is calculated, as well as its part occupied by the ferromagnetic elements $S_{e}=n_{y} m_{x} a_{e} b_{e}$. Then the filling factor of the working chamber according to the cross-sectional area is: $K_{F e s}=S_{e} / S_{s}$.

It is assumed that along the axial $z$ axis (Fig. 2,d), FEs are distributed with the same density as in the cross section. Then the same filling factor $K_{F e s}$ will be valid on this axis, which will be taken into account when calculating the MF in 2D formulation.

The total filling of the volume of the WC FE is characterized the volumetric filling factor $K_{F e v}=K_{F e s}^{2}$.

The components of the magnetic permeability along the two axes of the WC are determined by calculating the magnetic fields oriented along them. Such MFs are formed by setting the corresponding boundary conditions at the boundaries of the calculation model of the $\mathrm{WC}$ (Fig. 2,b) for the MVP $A_{z}$.

The boundary conditions for the formation of a longitudinal MF are:

$$
\left.A_{z}\right|_{g 2}=0 ;\left.A_{z}\right|_{g 4}=B_{a v} a_{s} ;\left.\frac{\partial A_{z}}{\partial y}\right|_{g 1}=0 ;\left.\frac{\partial A_{z}}{\partial y}\right|_{g 3}=0 \text {. }
$$

For the formation of a transverse MF, the boundary conditions are interchanged, namely:

$$
\left.A_{z}\right|_{g 1}=0 ;\left.A_{z}\right|_{g 3}=B_{a v} b_{s} ;\left.\frac{\partial A_{z}}{\partial x}\right|_{g 2}=0 ;\left.\frac{\partial A_{z}}{\partial x}\right|_{g 4}=0 \text {. }
$$

In (3) and (4), the MF excitation factor is the estimated mean value of MFD $B_{a v}$ in WC.

Inside the domain of the calculation model (Fig. 2,b), the MF is calculated using the FEMM code by the Finite Element Method by solving the 2D differential equation (2). In this case, the nonlinear magnetic properties of the FE elements, as well as the sparse structure of the calculation area along the axial axis, are taken into account by means of a certain filling factor $K_{\text {Fes. }}$.

For the test case, the values are taken: $d_{e}=1 \mathrm{~mm}$; $b_{e}=23.8 \mathrm{~mm} ; d_{x}=1.43 \mathrm{~mm} ; d_{y}=1 \mathrm{~mm} ; n_{y}=1$. Calculations using trivial formulas give: $m_{x}=9 ; a_{s}=21.9$ $\mathrm{mm} ; b_{s}=24.8 \mathrm{~mm} ; a_{e}=0.89 \mathrm{~mm} ; d_{x e}=1.54 \mathrm{~mm}$; $K_{\mathrm{Fes}}=0.35 ; K_{\mathrm{Fev}}=0.122$. It is for such a structure of the computational model, Fig. 3 shows the MF images at longitudinal $(a)$ and transverse $(b)$ excitation.

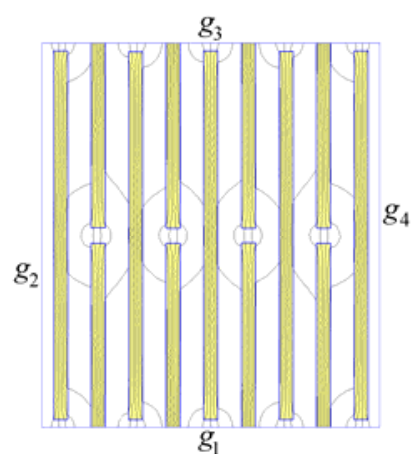

$a$

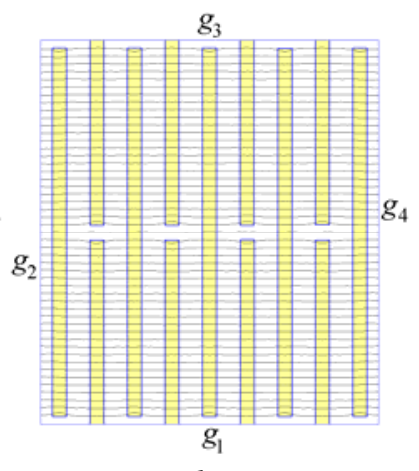

$b$
Fig. 3. Calculation model with longitudinal $(a)$ and transverse $(b)$ magnetic fields patterns

Using the magnetic field, the coordinate components of its strength $H_{x}$ and $H_{y}$ along the $x$ and $y$ axes are determined, and by them - the magnetic voltage drops along the vertical and horizontal lines:

$$
U_{\text {magd }}=\int_{0}^{b_{s}} H_{y} d y ; \quad U_{\text {magq }}=\int_{0}^{a_{s}} H_{x} d x,
$$

Then the average values of the components of this strength along the corresponding axes:

$$
H_{\text {yav }}=U_{\text {magd }} / b_{s} ; \quad H_{\text {xav }}=U_{\text {magq }} / a_{s}
$$

give the longitudinal and transverse components of magnetic permeability for an equivalent medium:

$$
\mu_{r d}=\frac{B_{a v}}{H_{y a v}} \cdot \frac{1}{\mu_{0}} ; \quad \mu_{r q}=\frac{B_{a v}}{H_{x a v}} \cdot \frac{1}{\mu_{0}} .
$$

Using here the magnetic constant $\mu_{0}$ allows to immediately go to the relative magnetic permeability (index $r$ has been added to identify this).

FEMM code provides obtaining $U_{\text {magd }}, U_{\text {magq }}, H_{\text {yav }}$ and $H_{x a v}$ values using a special procedure included in the Lua script. As a result, we obtained: $U_{\text {magd }}=1420 \mathrm{~A}$; $H_{\text {yav }}=19090 \mathrm{~A} / \mathrm{m} ; \mu_{r d}=10 ; U_{\text {magq }}=8640 \mathrm{~A}$; $H_{x a v}=122600 \mathrm{~A} / \mathrm{m} ; \mu_{r q}=1.5$.

In the general calculation area (Fig. 1), the magnetic field is described by the same equation (2) with setting in the WC of the detected magnetic anisotropy along the longitudinal and transverse axes. The propagation of the $\mathrm{MF}$ is limited by the outer surface of the inductor core, where the Dirichlet boundary condition is specified: $A_{z}=0$.

As an example, Fig. 1 shows the vector field of the MFD obtained in the load mode for the already determined values of magnetic permeability, time, and angle $\beta=45^{\circ}$. In this case, the current value $I_{s}$ was $455 \mathrm{~A}$ at phase voltage of the stator winding $U_{s}$ equal to $220 \mathrm{~V}$. At the central point of the working chamber, the MFD was $0.36 \mathrm{~T}$.

\section{Quantitative-phase} relationships of electromagnetic quantities in MFI. The determination or specification of these relationships is important and necessary in the calculation of the electromagnetic parameters and characteristics of the MFI presented below.

According to the results of the calculation of the MF using FEMM code [5], we obtain EMT through the Maxwell magnetic stress tensor according to the formula [9]: 


$$
M_{e m}=\frac{l_{a}}{\mu_{0}\left(r_{S}-r_{r}\right)} \int_{S_{\delta}} B_{r} B_{\alpha} r d S,
$$

where $B_{r}$ and $B_{\alpha}$ are the radial and angular components of the MFD, respectively; $r_{r}$ and $r_{s}$ are the radii of the circles limiting the cross-sectional area of the gap $S_{\delta}$ from the sides of the WC and the stator, respectively.

The basis of the analysis of electromagnetic values of the MFI is the operation with magnetic flux linkage (MFL) of the stator phase winding. This value is calculated by the distribution of the MVP [9] through the numerical implementation of the expression:

$$
\Psi=\frac{N_{s} l_{a}}{S_{\varphi}} \int_{S_{\varphi}} A_{z} d S \approx \frac{N_{s} l_{a}}{S_{\varphi}} \sum_{j=1}^{K_{\varphi}} A_{z, a v, j} \Delta S_{j},
$$

where $S_{\varphi}, K_{\varphi}$ are the cross-sectional area of all finite elements with current in the phase zone of the stator winding and the number of such elements; $A_{z, a v, j}$ is the average MVP value in the $j$-th element of the area $\Delta S_{j}$.

There is a special procedure in the FEMM code that provides the determination of MFL (9), which is automated under the control of the Lua script $[5,9]$.

After calculating the MF with its fixed structure, the «mask» of the stator phase winding is conditionally located alternately in the stator slots in different angular positions $\alpha_{k}$ with a shift by the tooth division.

In each position of the «mask», similarly to that described in [10], the MFL is determined by the formula (9) for all slots of the phase winding and a discrete angular function of the MFL is obtained:

$$
\Psi_{k}\left(\alpha_{k}\right), k=1,2, \ldots, K,
$$

where a sufficient number of positions $K=Q_{s} / 2$.

This periodic function is expanded into a harmonious Fourier series [8, 10], but for the purpose of this paper, the first harmonic of the MFL is enough:

$$
\Psi=\Psi_{m} \cos \left(\alpha+\gamma_{\psi}\right) \text {. }
$$

Due to the rotation of the MF with angular velocity $\Omega_{s}=\omega / p_{2}$ in (11) $\alpha$ is replaced by $\Omega_{s} t$, and for a stationary phase winding, the MFL becomes a temporary function:

$$
\Psi=\Psi_{m} \cos \left(\omega t+\gamma_{\psi}\right) \text {. }
$$

According to the law of electromagnetic induction, from (12) the EMF of the phase winding is obtained:

$$
e=\omega \Psi_{m} \cos \left(\omega t+\gamma_{\psi}-\pi / 2\right),
$$

where its amplitude $E_{m}=\omega \Psi_{m}$ and the initial phase $\gamma_{e}=\gamma_{\psi}-\pi / 2$ are separated.

Then the effective value of the EMF of the stator phase winding:

$$
E_{a}=\sqrt{2} \pi f_{s} \Psi_{m}
$$

The set of electrical quantities taken into account in the stator phase winding is represented using the equivalent circuit shown in Fig. 4.

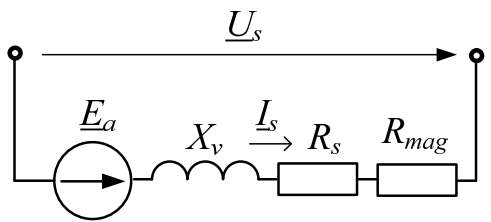

Fig. 4. Stator phase winding electrical equivalent circuit
In addition to the phase voltage $U_{s}$ and current $I_{s}$, in Fig. 4 the ideal source of the already determined EMF $E_{a}$ is located, as well as the ideal inductive and resistive elements characterized by the corresponding resistances: the active resistances $R_{s}$ and $R_{m a g}$ represent electric and magnetic power losses, the reactance $X_{v}-$ the frontal scattering of the stator winding MF. Other scattering fluxes are already taken into account in the MFL $\Psi$ (9), determined over the entire MF in the rectilinear part of the stator winding.

The resistances $R_{S}$ and $X_{v}$ are calculated according to the classical methods for calculating TAM [6].

To take into account the power of magnetic losses $P_{\text {mag }}$ in the circuit in Fig. 4, this active resistance introduced:

$$
R_{m a g}=\frac{P_{m a g}}{m_{s} I_{s}^{2}},
$$

and this power is determined in the stator core according to the updated method [11] after calculating the MF.

For the equivalent circuit (Fig. 4), the equilibrium voltage equation in a symbolic form is the following:

$$
\underline{U}_{S}=-\underline{E}_{a}-\underline{E}_{v}+\underline{U}_{R},
$$

where the EMF from the magnetic flux of frontal scattering and the voltage drop across the active resistances are presented

$$
\underline{E}_{v}=-j X_{v} \underline{I}_{S} ; \quad \underline{U}_{R}=\left(R_{S}+R_{\text {mag }}\right) \underline{I}_{S} .
$$

Quantitative and phase relationships of the already mentioned and also a number of electromagnetic quantities will be provided using the vector diagram (VD) in Fig. 5,a. It is built on the identified relationships of electromagnetic quantities in the MFI in compliance with generally accepted rules of electrical engineering.

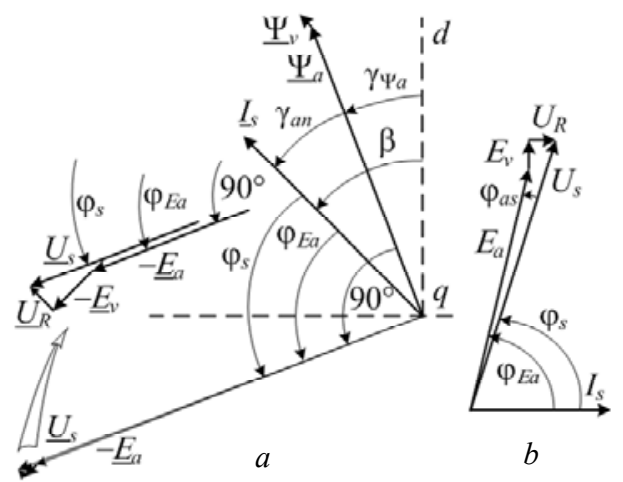

Fig. 5. Vector diagram of electrical and magnetic quantities of the stator phase winding

The angular coordinates are counted from the longitudinal axis of the WC $d$, which, as in Fig. 1, held vertically. Relative to it, the current vector $\underline{I}_{s}$ is drawn at the given angle $\beta$, and the MFL vector $\Psi_{a}$ which is in (12) is drawn at the angle of the initial phase $\gamma_{\psi a}$. The MFL vector of the frontal part of the winding $\underline{\Psi}_{v}$ is parallel to the vector $\underline{I}_{s}$. The EMF vector $\underline{E}_{a}$, according (13), is phase-ahead from $\underline{\Psi}_{a}$ by $90^{\circ}$, therefore the vector $-\underline{E}_{a}$ included in (16) is ahead of $\underline{\Psi}_{a}$ by $90^{\circ}$. According to (16), the $-\underline{E}_{v}$ vector is perpendicular, and the vector $\underline{U}_{R}$ is parallel to the current vector $\underline{I}_{s}$. The voltage vector $\underline{U}_{s}$ is constructed based on the summation of vectors according 
to (16). With respect to the current vector $I_{s}$, the vectors $-\underline{E}_{a}$ and $\underline{U}_{s}$ received leading phase shifts $\varphi_{s}$ and $\varphi_{E a}$, respectively.

The EMF value $E_{a}$ is found from (14), and the mentioned angle is found by the VD

$$
\varphi_{E a}=90^{\circ}-\gamma_{a n}=90^{\circ}-\beta+\gamma_{\psi a} .
$$

Then we can find $\underline{U}_{s}$ and $\varphi_{s}$. For clarity of this, a simplified (rotated and without scale) fragment of the VD is used (Fig. 5,b).

Active and reactive components of EMF $E_{a}$ :

$$
E_{a, a}=E_{a} \cos \varphi_{E a} ; \quad E_{a, r}=E_{a} \sin \varphi_{E a} .
$$

Similar voltage $U_{s}$ components:

$$
U_{s, a}=E_{a, a}-U_{R} ; \quad U_{s, r}=E_{a, r}-E_{v}
$$

give the actual value of the phase voltage and its phase shift relative to the current:

$$
U_{s}=\sqrt{U_{s, a}^{2}+U_{s, r}^{2}} ; \quad \varphi_{s}=\operatorname{arctg}\left(U_{s, r} / U_{s, a}\right) .
$$

As an example, we present the results of a test calculation carried out in relation to Fig. 1: $P_{\text {mag }}=1906 \mathrm{~W}$; $R_{\text {mag }}=0.00304 \Omega ; \Psi_{a}=0.938 \mathrm{~Wb} ; \gamma_{\Psi a}=21.09^{\circ} ; E_{a}=208 \mathrm{~V}$; $\varphi_{E a}=66.09^{\circ} ; \varphi_{s}=65.77^{\circ} ; E_{v}=10.1 \mathrm{~V} ; U_{R}=6.8 \mathrm{~V}$; $M_{e m}=324 \mathrm{~N} \cdot \mathrm{m}$. Separately, the values $R_{s}=0.00968 \Omega$ and $X_{v}=0.022 \Omega$ are determined.

It is from such data the picture of the distribution of MFD is a priori shown in Fig. 1and VD is built in Fig. 5,a. Additionally, Fig. 6 shows a picture of the magnetic force lines of the $\mathrm{MF}$ and the mutual correspondence of the mentioned rotation angles of different quantities for the considered MFI load mode.

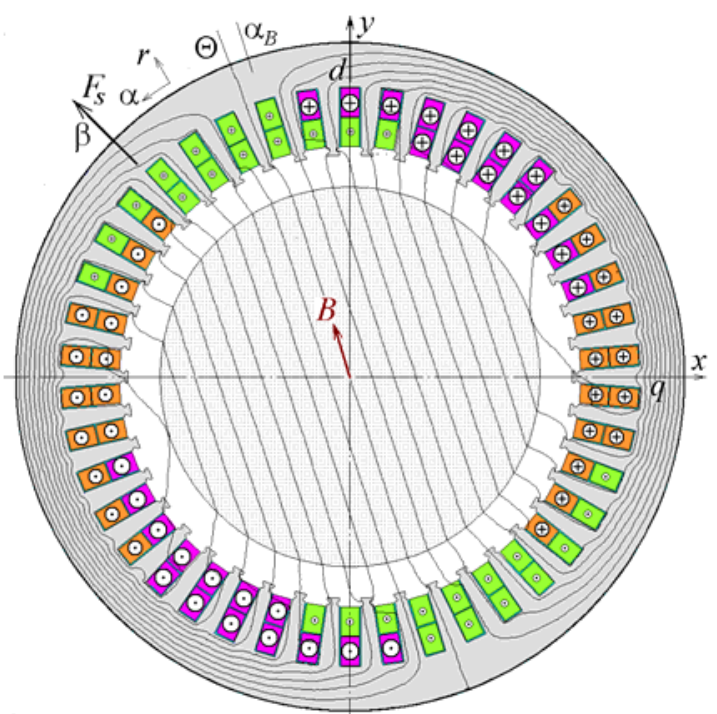

Fig. 6. MF picture in the form of force lines and angle marks for different quantities

It is noteworthy that the angle $\gamma_{\Psi a}$ turned out to be substantially smaller than $\beta$. At the same time, it was revealed that, given $\beta=0$, the value $\gamma_{\Psi a}$ also turned out to be zero, and this corresponded to the II mode, since the EMT by (8) was zero. The rotation of the MFL vector $\underline{\Psi}_{a}$ from the II mode to the load mode, according to the theory of synchronous machines [8], is the load angle. Therefore, the angle $\gamma_{\Psi a}$ in Fig. 5,a is nothing other than the MFI load angle, i.e. $\Theta=\gamma_{\Psi a}$, which is also shown in Fig. 6.
The angle of rotation of the vector $\vec{B}$ is determined by the coordinate components of the MFD vector in the center of the WC:

$$
\alpha_{B}=\operatorname{arctg}\left(B_{x} / B_{y}\right),
$$

which is $15.1^{\circ}$.

Energy parameters of MFI. After calculating the MF and determining the quantitative and phase relationships of electromagnetic quantities, it is enough to quite simple calculate the energy parameters of the MFI.

Electromagnetic power in electrical terms:

$$
P_{e m}=m_{s} E_{a} I_{s} \cos \varphi_{E a} .
$$

On the other hand, electromagnetic power in mechanical terms can be considered as output or useful power:

$$
P_{\text {em }}=P_{\text {out }}=M_{\text {em }} \Omega_{s}
$$

Input or expended power:

$$
P_{s}=m_{s} U_{s} I_{s} \cos \varphi_{s},
$$

where the power factor $\cos \varphi_{s}$ is determined by the phase shift of the voltage and current of the stator winding calculated in accordance with (21).

Power losses are composed of the power of electrical losses in the stator winding.

$$
P_{e l}=m_{s} R_{s} I_{s}^{2}
$$

and the aforementioned magnetic losses power $P_{\text {mag }}$ in the stator core.

Efficiency of the MFI:

$$
\eta=P_{\text {out }} / P_{\text {in }}
$$

Characteristics of MFI. The presented theoretical base allows to calculate a number of characteristics of the MFI, connecting its electromagnetic and energy parameters, as well as the phase relationships of the corresponding quantities in the mode of a changing load. When studying characteristics, the basic ones are traditionally selected from the set of figures, while the rest are analyzed.

In MFI, the basic ones include voltage $U_{s}$ and current $I_{s}$ of the stator winding, which are input values for it. In this case, two variants of operation with a change in load are possible:

1) the effective current value $I_{s}$ is kept constant, and the voltage and other values are calculated;

2) the effective value of the voltage $U_{s}$ is kept constant, and the current and other values are calculated.

In the first case, the effective operation of the MFI at the maximum permissible level for electric losses of the stator winding power and its heating is possible, but an appropriate voltage regulator is required. In the second case, we can use the existing power supply network to power, but the stator winding and the MFI can operate in a given load range with insufficient use.

In this paper, we consider the first variant of the operation of the MFI - with the stabilization of the current value of the stator winding, leaving the second option to continue research in the following works.

At a stable value of the stator winding current, a change in the mechanical load with a change in the filling of the WC leads to a change in the EMT due to a change in the load angle and other phase relationships. Of these, for calculating the characteristics, as a variable quantity - 
argument it is convenient to take the angle of the generalized initial phase of the stator winding currents $\beta$ included in (1).

Then the solution of the problem of calculating the characteristics becomes quite simple: when setting the effective value of the current $I_{s}$ and angle $\beta$, the MF is calculated and, according to the method expressed by formulas (1)-(27), a whole series of necessary values is obtained.

To obtain various characteristics from the calculated numerical arrays of different quantities, some of them can later be taken as an independent argument and from others - functions that are of interest to the calculator can be assigned.

In a specific calculation example of characteristics, the base value of the current $I_{s}=455 \mathrm{~A}$ is accepted, which was already used in the test calculation at $\beta=45^{\circ}$ and $U_{s}=220 \mathrm{~V}$.

To obtain the full characteristics, the angle $\beta$ range from 0 to $90^{\circ}$ is adopted, which for sufficient «smoothness» of the graphs is carried out with a step of $5^{\circ}$.

The main part of the obtained characteristics is presented in Fig. 7-10. Their essence is manifested by the quantities indicated on the graphs.

We draw attention to the fact (Fig. 8) that the angles $\beta$ and $\Theta$ coincide in values at the extreme points -0 and $90^{\circ}$. In this case, the EMT is zero, that is, the II mode takes place. The maximum EMT value corresponds to the angle $\beta=46^{\circ}$ (Fig. 7), and here the critical load angle $\Theta_{c r}$ is $22.5^{\circ}$ (Fig. 8).

According to the theory of synchronous machines, in the range of the angle $\Theta$ from 0 to $\Theta_{c r}$, the operating mode of the MFI is stable. In order to have a twofold EMT margin, the load angle $\Theta_{\text {nom }}$ equal to about $7^{\circ}$ can be considered nominal, which corresponds to the angle $\beta=17-18^{\circ}$.

Figure 7 shows that from II to this angle, the voltage, MFL, EMF and resistance $R_{\text {mag }}$ are approximately stable - with a slight decrease with increasing load of the MFI. The same can be said about magnetic losses (Fig. 9), and electric losses are unchanged by definition, due to the stability of the current.

The electromagnetic power in electrical (23) and mechanical (24) expressions is numerically identical (Fig. 9), which can be considered as a check of the correctness of the obtained phase relationships of electrical quantities. The shape of the graphs of these powers is naturally similar to the EMT graph.

The characteristics of the power factor and efficiency (Fig. 10) show their natural growth with increasing load of the MFI. The level of efficiency in the range of stable operation corresponds to the classic electric machines of low and medium power. But the level of the power factor turns out to be very small, which is explained by the presence of large nonmagnetic gaps and a low-magnetic medium in the WC.

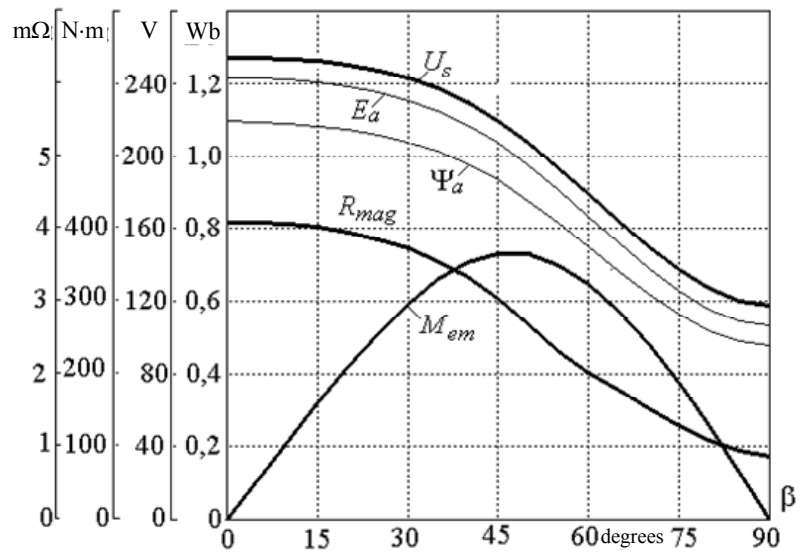

Fig. 7. Characteristics of voltage, MFL, EMF, EMT and active resistance to take into account magnetic losses

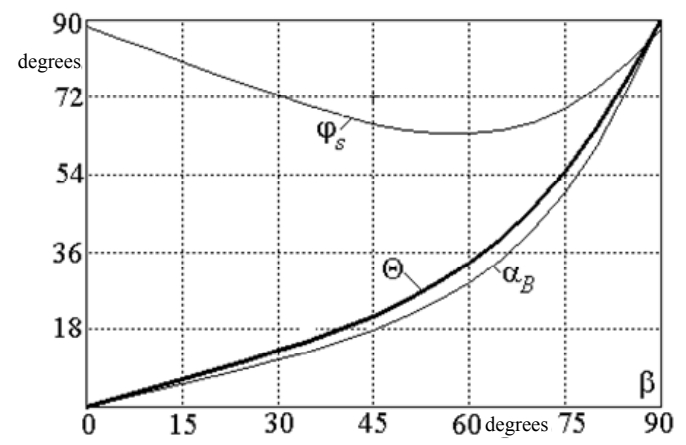

Fig. 8. Characteristics of phase relationships in MFI

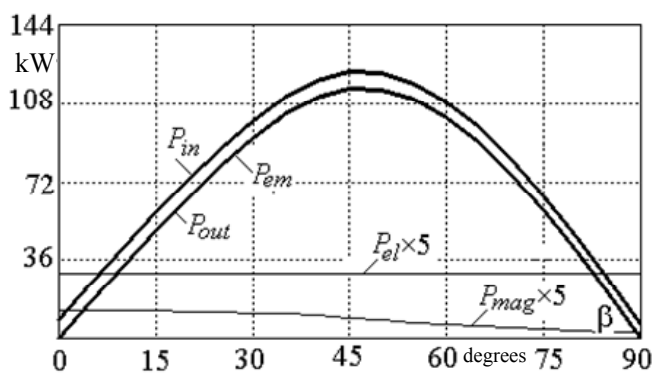

Fig. 9. Characteristics of powers and power losses

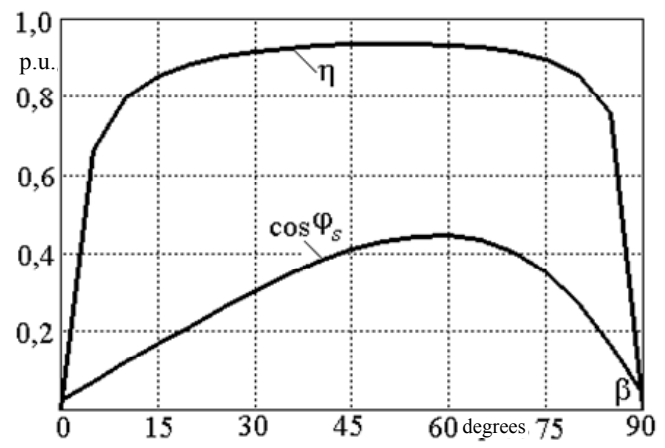

Fig. 10. Characteristics of power factor and efficiency

\section{Conclusions.}

1. Numerical-field calculation allows to accurately take into account the geometric shapes of the stator core of the MFI, its nonlinear magnetic properties and the anisotropy of the magnetic properties of the working chamber with oblong ferromagnetic elements.

2. The considered phase relationships of electromagnetic and force quantities show that, according 
to the principle of operation, in the composition of the device for processing various substances, the MFI is closest to a synchronous motor.

3. One of the key elements of the developed theory and methodology for calculating electromagnetic parameters, their phase relationships and MFI characteristics is the proposed method for taking into account the magnetic anisotropy of its working chamber with filling with ferromagnetic elements.

4. In the area of stable operation, in energy terms the MFI is characterized by a rather high efficiency and a very low value of power factor. The latter is due to the presence of large gaps and a law-magnetic medium in the working chamber in the inductor's magnetic system.

5. The developed methodology for numerical-field calculations of characteristics gives a lot of useful information that can be used to design and improve MFI.

\section{REFERENCES}

1. Logvinenko D.D., Sheljakov O.P. Intensifikacija tehnologicheskih processov $v$ apparatah $s$ vihrevym sloem [Intensification of technological processes in apparatus with a vortex layer]. Kiev, Tehnika Publ, 1976. 144 p. (Rus.)

2. Zagirnyak M.V., Branspiz Yu.A., Shvedchikova I.A Magnitnye separatory. Problemy proektirovanija. [Magnetic separators. Design issues]. Kiev, Tehnika Publ, 2011. 224 p. (Rus.)

3. Kompanija GlobeCore. Apparat Vihrevogo Sloja AVS-100. [Company GlobeCore. Vortex Layer Machine ABC-100] Available at: https://avs.globecore.ru/products/avs-100.html (accessed 30.09.2017).

4. Milykh V.I., Shilkova L.V. Revuzhenko S.A. Numerical analysis of the magnetic field of a cylindrical three-phase magnetic separator inductor. Bulletin of NTU «KhPI». Series: «Electric machines and electromechanical energy conversion», 2017, no.1(1123), pp. 76-82. (Ukr.)

How to cite this article:

Milykh V.I., Shilkova L.V. Numerical-field analysis of the characteristics of a three-phase magnetic field inductor for the treatment of various substances with current stabilization. Electrical engineering \& electromechanics, 2019, no.6, pp. 21-28. doi: 10.20998/2074-272X.2019.6.03.
5. Finite Element Method Magnetics: OldVersions. FEMM 4.2 $110 c t 2010$ Self-Installing Executable. Available at: http://www.femm.info/wiki/OldVersions (accessed 15.06.2017).

6. Kopylov I.P., Goryainov F.A., Klokov B.K. Proektirovanie elektricheskih mashin [The design of electrical machines]. Moscow, Yurait Publ., 2011. 767 p. (Rus)

7. Milykh V.I. The system of automated formation of electrical machines computational models for the FEMM software environment. Technical Electrodynamics, 2018, no.4, pp. 74-78. (Ukr.) doi: 10.15407/techned2018.04.074.

8. Voldek A.I., Popov V.V. Elektricheskie mashiny. Mashiny peremennogo toka [Electrical machines. AC machines]. SPb, Piter Publ., 2010. 356 p. (Rus).

9. Milykh V.I., Polyakova N.V. Determination of electromagnetic parameters of electric machines based on numerical calculations of magnetic field. Electrical engineering \& electromechanics, 2006, no.2, pp. 40-46. (Rus).

10. Milykh V.I. Numerically-field analysis of the adequacy of the design data of three-phase induction motors and the method of their refinement on this basis. Technical Electrodynamics, 2018, no.1, pp. 47-55. (Rus) doi:

10.15407/techned2018.01.047.

11. Milykh V.I., Shilkova L.V. The numeral-field analysis of power of magnetic losses is in the three-phase inductor of magnetic-field. Bulletin of NTU «KhPI». Series: "Electric machines and electromechanical energy conversion», 2019, no.4(1329), pp. 99-106. (Ukr.) doi: 10.20998/24099295.2019.4.15.

Received 02.09.2019

V.I. Milykh ${ }^{1}$, Doctor of Technical Science, Professor,

L.V. Shilkova ${ }^{1}$, Postgraduate Student,

${ }^{1}$ National Technical University «Kharkiv Polytechnic Institute», 2, Kyrpychova Str., Kharkiv, 61002, Ukraine, phone +380 0577076514 ,

e-mail: mvikemkpi@gmail.com, larisa_lv@ukr.net 